\title{
BMJ Open VaccHemInf project: protocol for a prospective cohort study of efficacy, safety and characterisation of immune functional response to vaccinations in haematopoietic stem cell transplant recipients
}

Anne Conrad, ${ }^{1,2,3}$ Mathilde Boccard, ${ }^{1,2,3}$ Florent Valour, ${ }^{1,2,3}$ Vincent Alcazer, ${ }^{3,4}$ Aydee-Tamara Tovar Sanchez, ${ }^{5,6}$ Christian Chidiac, ${ }^{1,3}$ Frédéric Laurent, , ${ }^{1,2,7}$ Philippe Vanhems, ${ }^{2,3,5,6}$ Gilles Salles, ${ }^{3,4}$ Karen Brengel-Pesce, ${ }^{8}$ Boris Meunier, ${ }^{8,9}$ Sophie Trouillet-Assant, ${ }^{2,3,8,10}$ Florence Ader, ${ }^{1,2,3}$ on behalf of the Lyon HEMINF Study Group

To cite: Conrad A, Boccard M, Valour F, et al. VaccHemlnf project: protocol for a prospective cohort study of efficacy, safety and characterisation of immune functional response to vaccinations in haematopoietic stem cell transplant recipients. BMJ Open 2019;9:e26093. doi:10.1136/ bmjopen-2018-026093

- Prepublication history for this paper is available online. To view these files, please visit the journal online (http://dx.doi. org/10.1136/bmjopen-2018026093).

Received 16 August 2018 Revised 6 November 2018 Accepted 7 November 2018

Check for updates

(C) Author(s) (or their employer(s)) 2019. Re-use permitted under CC BY-NC. No commercial re-use. See rights and permissions. Published by BMJ.

For numbered affiliations see end of article.

Correspondence to

Dr Florence Ader;

florence.ader@chu-lyon.fr

\section{ABSTRACT}

Introduction Immune reconstitution after haematopoietic stem cell transplantation (HSCT) is a complex and dynamic process, varying from a state of nearly complete immunosuppression to an expected full immune recovery. Specific vaccination guidelines recommend reimmunisation after HSCT but data regarding vaccine efficacy in this unique population are scarce. New immune functional assays could enable prediction of vaccine response in the setting of HSCT.

Methods and analysis A prospective, longitudinal single-centre cohort study of autologous and allogeneic HSCT recipients was designed in order to determine the vaccine response to five vaccine targets (pneumococcus, hepatitis B virus, Haemophilus Influenzae type b, tetanus and diphtheria) and to correlate it to immune function parameters. A workflow was set up to study serological response to vaccines and to describe the functional immune status of 100 HSCT recipients (50 autologous and 50 allogeneic) before and 3,12 and 24 months after primary immunisation. At each time point, 'basic' immune status recording (serology, immunophenotyping of lymphocyte subsets by flow cytometry) will be assessed. The immune response will furthermore be evaluated before and 3 months after primary vaccination by two ex vivo immune functional assays assessing: (1) tumour necrosis factor alpha, interferon gamma production and host messenger RNA expression on whole-blood stimulation by lipopolysaccharide or Staphylococcus aureus enterotoxin B and (2) T-lymphocyte proliferation in response to a standard mitogen (phytohaemagglutinin) or to selected recall antigens. Reference intervals will be determined from a cohort of 30 healthy volunteers. This translational study will provide data describing vaccine response, immune functionality of HSCT recipients over time and will allow mapping HSCT recipients with regard to their immune function.
Strengths and limitations of this study

This is a prospective study to describe the response to five major vaccines among a cohort of adult autologous and allogeneic haematopoietic stem cell transplantation (HSCT) recipients in a 'real-life' setting.

- Secondary outcomes of this study will offer opportunity to assess the impact of pretransplant and post-transplant factors (ie, graft-vs-host disease) as well as of functional immune status of HSCT recipients on vaccine response.

- Innovative immune functional assays will assess innate and adaptive immune response of HSCT recipients at the transcriptomic, protein and cellular level before and 3 months after primary vaccination.

- Immunisation will be initiated on haematologist's referral, which might create a bias of inclusion and impact vaccine response.

- Biomarkers of immune functionality could help to optimise vaccine schedules at an individual level, but this will have to be addressed and validated in further specific studies.

Ethics and dissemination Ethical approval has been obtained from the institutional review board (no 69HCL17_0769). Results will be communicated at scientific meetings and submitted for publication in peerreviewed journals.

Trial registration number NCT03659773; Pre-results.

\section{INTRODUCTION}

Haematopoietic stem cell transplantation (HSCT) is a cellular therapy aiming at curing malignant and non-malignant 
haematological diseases. ${ }^{1-3}$ Allogeneic HSCT is based on the transfer of an immune system from a donor to a recipient through replacement of haematopoietic stem cells for diseases such as acute leukaemia or thalassaemia major that are otherwise refractory to treatment. Autologous HSCT is based on the reinjection of recipients' own immune system ensuing intensive chemotherapy for diseases such as multiple myeloma or aggressive lymphoma. On HSCT, recipients experience a phase of profound immunosuppression with loss of protective immunity against most infectious agents followed by gradual immune recovery. ${ }^{2}$ Infections are among the most frequent complications after HSCT, and consequently, key players for recipients' outcome. ${ }^{2}$ Indeed, infections are the second cause of death for both autologous and allogeneic HSCT beyond day 100 post-transplant. ${ }^{5}$ Reimmunisation of HSCT recipients against vaccine-preventable infections is an important post-transplant intervention for reducing morbimortality. ${ }^{6}$ Consistently, vaccination schedules have been proposed by various expert committees, based on epidemiology of vaccine-preventable diseases and the relatively few data available on efficacy, safety and effectiveness of vaccines in the HSCT setting. ${ }^{6-11}$ However, some studies have suggested that patients with haematological malignancies and an impaired immune status might benefit, especially for influenza, from additional vaccine doses to those recommended at present. ${ }^{12}{ }^{13}$ Therefore, addressing vaccine response obtained in HSCT recipients in a 'reallife' setting with the currently recommended vaccination schedule is an important issue.

Studies have brought evidence of immune responsiveness to vaccines after HSCT, referred to as vaccine efficacy. The reference method for assessing vaccine efficacy is the measurement of serum antibody titres. Nonetheless, antibody titres do not correlate accurately with clinical protection, in addition to the issue of durability of protection. ${ }^{14}$ Given the complexity and heterogeneity of HSCT recipients, it is unlikely that a single biomarker is sufficient to assess vaccine-induced protection. A panel of validated operational biomarkers may bring enough information to achieve such a goal. Moreover, immune recovery is a highly dynamic process, and it is unlikely that all recipients fit into a single pattern of reimmunisation: on the one hand, some HSCT recipients, according to their functional immune status, might require delayed initiation of their reimmunisation schedule and/or higher amounts of vaccine antigens (ie, multiple vaccine doses) to improve response to vaccination. On the other hand, some HSCT recipients with rapid and goodquality immune reconstitution might benefit from an earlier implementation of the vaccination schedule. The various pretransplant and post-transplant factors influencing immune recovery and immunisation response might consequently be included in more personalised post-transplant vaccination schedules.

\section{Rationale}

The VaccHemInf project aims to assess the efficacy of recommended vaccines in adult patients undergoing autologous or allogeneic HSCT, challenging the antibody titre reference method by a panel of immune functional assays measuring at different time points cellular immune responsiveness to standardised antigens and vaccines. Our hypothesis is that many pretransplant and post-transplant factors are involved in the vaccine response, which may be altered durably after HSCT. Consequently, a panel of immune functional assays may best predict vaccine efficacy at the individual level.

\section{Objectives}

We have assigned two objectives to the VaccHemInf project: (1) to assess efficacy of five major vaccines (pneumococcus, hepatitis B virus (HBV), Haemophilus Influenzae type $b$, tetanus and diphtheria) administrated after HSCT using the antibody titre reference method in a 'real-life' setting, in correlation with multiple variables related to haematological characteristics, treatment management, pattern of post-transplant immune recovery and transplant-related complications; (2) to evaluate innovative ex vivo immune functional assays testing biomarkers aiming at measuring vaccine-specific response. This part of the VaccHemInf project is named Fonctionnalité Immunitaire après Greffe de cellules souches $\underline{\text { HématopoïéTiques }}$ (FIGHT).

\section{Deliverables}

The assigned agenda is to measure sequentially the functional innate and adaptive immune response to five vaccines and to identify transplant-related factors associated with low or no immunisation. 'Mapping' the recipients of HSCT on an immunological scale would allow predicting vaccine efficacy, and ultimately establish a personalised standard of care for vaccinations based on recipient immune recovery record.

\section{METHODS AND ANALYSIS \\ Study design}

The VaccHemInf project is a single-centre prospective, consecutive cohort of adult HSCT recipients transplanted at the Haematology department of a 5362-bed tertiary-care university hospital (Lyon, France). During the past 5 years, the 114-bed Haematology department carried out an average of 102 (range, 90-110) and 81 (range, 73-88) autologous and allogeneic HSCT yearly, respectively.

\section{Setting}

On referent haematologist's agreement, eligible adult (autologous or allogeneic) HSCT recipients will be referred to the vaccination centre dedicated to immunocompromised patients hosted by the Infectious Diseases department of Lyon's university hospital for inclusion in the VaccHemInf cohort. The recruitment period will be of 24 months and recipient overall follow-up will cover 

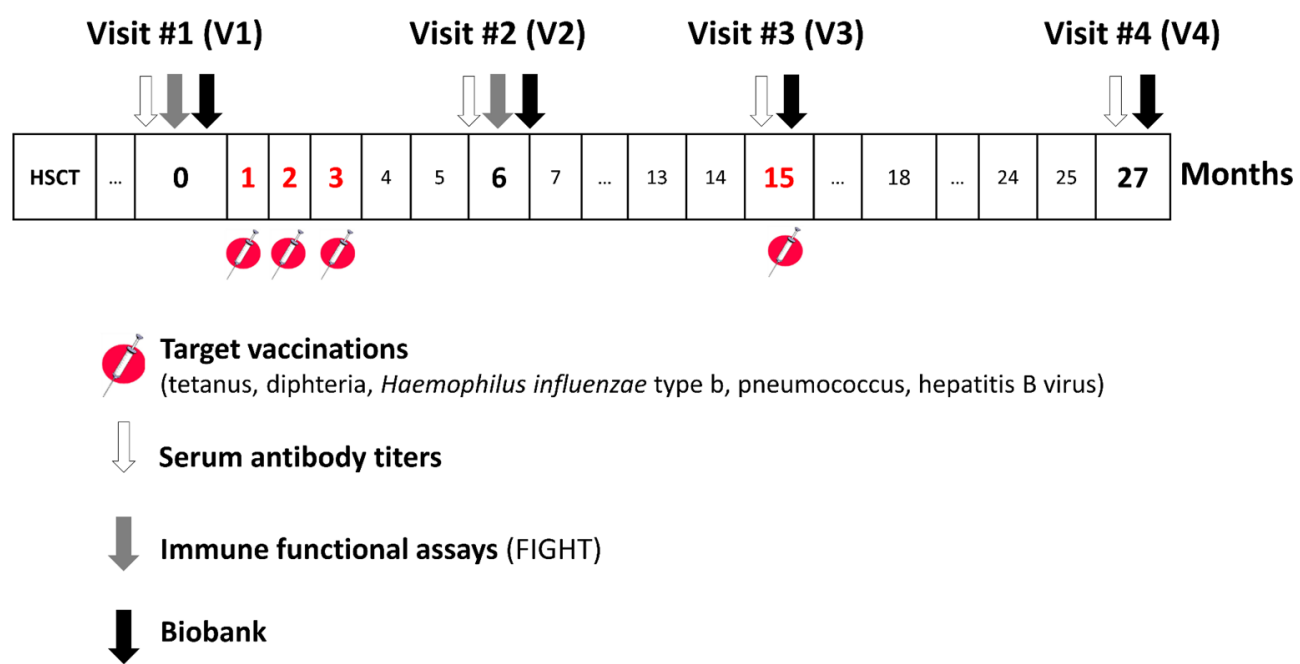

Figure 1 Workflow of vaccines and sampling schedule of the VaccHemlnf cohort. FIGHT, Fonctionnalité Immunitaire après Greffe de cellules souches HématopoïéTiques; HSCT, haematopoietic stem cell transplantation.

a period of 48 months. For the purpose of FIGHT, 30 control healthy volunteers will be enrolled and will be tested for immune functional assays. Healthy volunteers will be recruited among the donors to the blood bank of the Etablissement Français du Sang (EFS) of Lyon. According to the EFS standardised procedures for blood donation, informed consent will be obtained from healthy donors, and personal data will be anonymised at the time of blood donation prior to the transfer of blood to the research laboratory.

\section{Participants}

The workflow of the VaccHemInf cohort is described in figure 1. Recipients aged 18 years or more will be included. During the first visit (V1), explanations will be given on: (1) implementation of the vaccination schedule and preblood test assessment and (2) postvaccination assessments at the 3 months (V2), 12 months (V3) and 24 months (V4) visits to monitor vaccine response and tolerance. FIGHT immune functional assays will only be performed at V1 and V2, as described in the workflow presented in figure 2. Exclusion criteria will apply in case of post-transplant relapse of the haematological underlying disease or in case of recipients' death.

\section{Endpoints}

To address the objectives mentioned above, the primary endpoint will be to measure vaccine-specific antibody titres and to express vaccine response in percentage of responders and geometric mean titres (GMTs) immediately before and at 3,12 and 24 months after vaccinations.

Secondary endpoints will be: (1) to investigate immune status before and 3,12 and 24 months after vaccinations through the routine immunomonitoring and FIGHT new

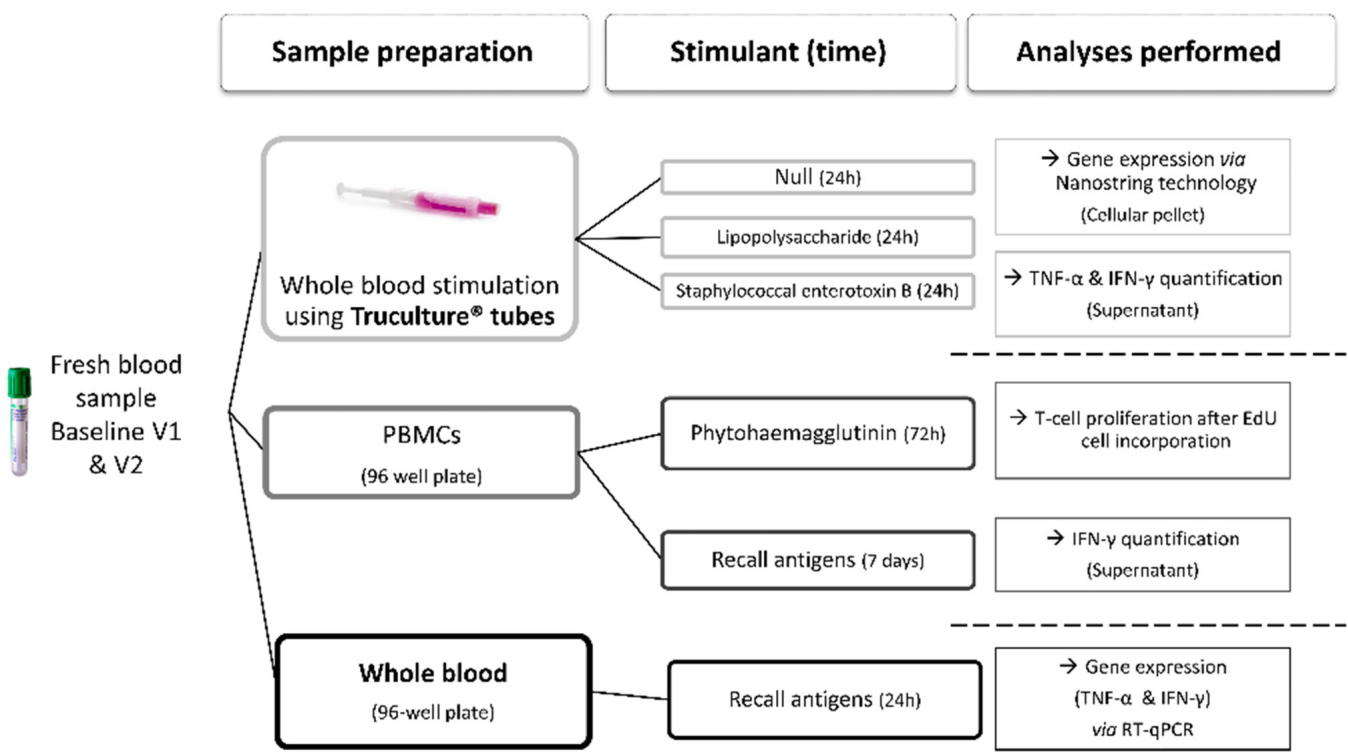

Figure 2 Workflow of the immune functional assays ('FIGHT') of the VaccHemlnf cohort. EdU, 5-ethynyl-2'-deoxyuridine; FIGHT, Fonctionnalité Immunitaire après Greffe de cellules souches HématopoïéTiques; IFN- $\gamma$, interferon gamma; PBMCs, peripheral blood mononuclear cells; RT-qPCR, real-time reverse transcription PCR; TNF- $\alpha$, tumour necrosis factor alpha. 


\section{Box 1 List of pretransplant variables}

Age at transplantation

Gender

Comorbidities

- $\mathrm{HCT}_{-\mathrm{Cl}}{ }^{15}$

D Diabetes mellitus.

- Tobacco smoking (active/stopped, pack per year).

- Chronic pulmonary disease.

- Chronic heart condition.

- Chronic neurological condition.

- Autoinflammatory disease.

Underlying haematological diseases

- Acute myeloid leukaemia/myelodysplastic syndrome.

- Acute lymphoblastic leukaemia.

- Myeloproliferative neoplasms.

- Acquired bone marrow failure syndrome.

- Lymphoproliferative neoplasms/multiple myeloma.

Anti-HLA antibodies

- Positive/negative.

Donor specific.

Splenectomy/functional hyposplenism

HCT-CI, Haematopoietic Cell Transplantation Comorbidity Index.

immune functional assays; (2) to thoroughly document vaccine safety; (3) to implement an exhaustive prospectively maintained database including variables related to the above endpoints.

\section{Variables}

The following data will be exhaustively recorded in a VaccHemInf-specific numerical clinical record folder (e-CRF): demographics, comorbidities using the Haematopoietic Cell Transplantation Comorbidity Index ${ }^{15}$ and haematological underlying conditions (box 1). The transplant characteristics will include disease status at transplantation, prior transplantation(s), conditioning regimen, graft cellularity, donor type, donor HLA matching, stem cell source, graft-versus-host disease (GVHD) prophylaxis including post-transplant cyclophosphamide for haploidentical transplants, and donor and recipient serostatus for cytomegalovirus, EpsteinBarr virus and toxoplasmosis (box 2). The post-transplant characteristics will include time to engraftment, second graft when appropriate, occurrence and grade of acute GVHD and its treatment, occurrence and grade of chronic GVHD according to the last National Institutes of Health Consensus criteria and its treatment, ${ }^{16}{ }^{17}$ opportunistic infections of bacterial, fungal, viral or parasitic origin occurring on conditioning (day 7 before HSCT) and after HSCT using the European Group for Blood and Marrow Transplantation classification for infections, infectious agent-related reactivations and diseases (updated with the latest guidelines, and which list and full definition criteria are provided in table 1), ${ }^{18-32}$ peripheral blood T-lymphocytes and B-lymphocytes subsets and natural killer counts (box 3). Event variables will correspond to the applied French vaccination schedule (table 2). ${ }^{7}$ The responses to vaccines are defined as follows: for pneumococcus, a

\section{Box 2 List of transplant variables}

\section{Disease status at transplantation}

- Early.

- Intermediate.

- Advanced.

Prior transplantation(s)

\section{Gender mismatch}

- Male recipient with female donor.

\section{Conditioning regimen \\ - Myeloablative. \\ - Reduced intensity. \\ - Total body irradiation (yes/no, dose).}

\section{Graft cellularity}

Total nucleated cells

- Bone marrow $/$ peripheral blood $\left(10^{8} \mathrm{cells} / \mathrm{kg}\right)$.

- Cord blood $\left(10^{7}\right.$ cells $\left./ \mathrm{kg}\right)$.

CD34+ cells

- Bone marrow/peripheral blood $\left(10^{6} \mathrm{cells} / \mathrm{kg}\right)$.

- Cord blood $\left(10^{5} \mathrm{cell} / \mathrm{kg}\right)$.

$\mathrm{CD} 3+$ cells $\left(10^{6} \mathrm{cell} / \mathrm{kg}\right)$

\section{ABO mismatch \\ - No mismatch. \\ - Major. \\ - Minor. \\ - Bidirectional.}

\section{Donor HLA matching}

- Matched sibling.

- Matched unrelated donor.

- Mismatched unrelated donor.

- Cord blood (matched or mismatched).

- Haploidentical.

\section{Stem cell source}

- Bone marrow.

- Peripheral blood mobilised stem cells.

- Cord blood.

Graft-versus-host disease prophylaxis

- Antithymocyte globulins.

- Ciclosporin.

- Tacrolimus.

- Methotrexate.

- Mycophenolate mofetil.

- Cyclophosphamide.

- Methylprednisolone.

\section{Donor and recipient serostatus}

- Cytomegalovirus.

- Epstein-Barr virus.

- Toxoplasmosis.

- Hepatitis B virus.

30-270 mg/L IgG titre corresponds to a healthy population range (supplier data). In immunocompetent adults vaccinated with the 23-valent non-conjugated pneumococcal vaccine, the median increase in IgG titre was 4.7 (IQR, 2.7-6.6) times. ${ }^{3-35}$ Consequently, a fourfold increase in the IgG titre will be considered significant to 
Table 1 EBMT classification of infections and current criteria for infections, infectious agent-related reactivations and diseases according to the latest consensus of reference definitions for each infection

\section{Type of infection}

Fungal

\section{References}

Aspergillus spp diseases ${ }^{19}$

Candida spp diseases ${ }^{20}$

Mucormycosis ${ }^{2}$

Hyalohyphomycosis-related diseases ${ }^{22}$

Pneumocystis jirovecii pneumonia ${ }^{23}$

Viral

Were excluded: directly treated low viral load $\left(<3 \log _{10}\right.$ copies/ $\mathrm{mL}$ for CMV/HHV-6, $<4 \log _{10} \mathrm{UI} / \mathrm{mL}$ for EBV, evidence of BK virus in urine without symptoms nor BK viraemia)

\section{$\mathrm{EBV}^{24}$}

$\mathrm{CMV}^{25} 26$

HHV- $6,-7,-8^{25}$

BK virus ${ }^{27}$
Adenovirus $^{28}$

Influenza virus ${ }^{29}$

Community-acquired respiratory viruses ${ }^{30}$

\author{
Bacterial infections
}

BSI without organ dysfunction

BSI with at least one organ dysfunction: according to 2016

Sepsis-3 criteria $^{31}$ :

Sepsis (qSOFA and SOFA $\geq 2$ )

Septic shock

Parasitic

Sepsis of unknown origin

\section{Toxoplasmosis $^{32}$}

$\geq 5$ days persistent fever $\left(\geq 38.5^{\circ} \mathrm{C}\right)$ under appropriate antiinfectious agent escalation, without any documentation.

BSI, blood stream infection; CMV, cytomegalovirus; EBMT, European Group for Blood and Marrow Transplantation; EBV, Epstein-Barr virus; $\mathrm{HHV}$, human herpes virus; SOFA, sepsis-related organ failure assessment.

reach immunisation. For $H$. influenzae type b, serology has no definite critical value. In immunocompetent adults vaccinated with the $H$. influenzae type b conjugate vaccine, the median increase in IgG titre was 5 (IQR, 3.5-7) times. ${ }^{35}{ }^{36}$ Consensually, values between 0.15 and $1 \mu \mathrm{g} / \mathrm{mL}$ will be considered to be short-term protective, with a linearity limit of $9 \mu \mathrm{g} / \mathrm{mL} .{ }^{36}{ }^{37}$ An IgG titre higher than the standard protection threshold will be considered protective for tetanus and diphtheria $(\geq 0.1 \mathrm{IU} / \mathrm{mL})$ and HBV (anti-HBs antibody titre $>10 \mathrm{mIU} / \mathrm{mL}$ ). ${ }^{38} \mathrm{An}$ anti-HBs titre $>100 \mathrm{IU} / \mathrm{mL}$ will be considered to confer long-lasting protection. ${ }^{39}$

\section{FIGHT immune functional assays}

To investigate innate and adaptive immune responses, two standardised immune functional assays will be carried out based on the findings of the REALISM project, which has established reference intervals in a large cohort of healthy volunteers. ${ }^{40}$ Briefly, the first immune functional assay will consist in collecting whole blood samples using the standardised TruCulture system (Myriad RBM, Austin, Texas, USA) directly containing immunogenic stimuli: medium alone (Null), lipopolysaccharide (LPS) at $100 \mathrm{ng} / \mathrm{mL}$ (from Escherichia coli O55:B5), and Staphylococcus aureus enterotoxin $\mathrm{B}(\mathrm{SEB})$ at $0.4 \mu \mathrm{g} / \mathrm{mL}$, respectively. ${ }^{41}$ On a 24 -hour stimulation at $37^{\circ} \mathrm{C}$, the supernatant and the pellet will be collected using the separation valve. The supernatant will be stored at $-80^{\circ} \mathrm{C}$ until batch serial quantification of cytokines tumour necrosis factor alpha $(\mathrm{TNF}-\alpha)$ and interferon gamma (IFN- $\gamma$ ) with Simple plex cartridges (ProteinSimple, San Jose, California, USA) using the ELLA platform (ProteinSimple). The cellular pellet will be stabilised in $2 \mathrm{~mL}$ of Trizol LS (Sigma Aldrich, Saint Louis, Missouri, USA) and the messenger RNA (mRNA) will be isolated with the NucleoSping 96 RNA tissue kit (Macherey-Nagel, Düren, Germany) for analysis of mRNA expression using the nCounter technology (NanoString Technologies, Seattle, Washington, USA), consisting in an RNA hybridisation method, whose gene set can include up to 780 genes. ${ }^{41} 42$

The second immune functional assay will consist in inducing T-lymphocyte proliferation and measuring IFN- $\gamma$ release in the supernatant in response to an ex vivo stimulation with a standard mitogen, phytohaemagglutinin (PHA). Peripheral blood mononuclear cells (PBMCs) will be isolated from fresh, heparinized blood samples by Ficoll density gradient centrifugation (U-04; Eurobio, Les Ulis, France) and will be incubated with culture medium overnight. Then, PBMCs will be stimulated in duplicate with PHA at $4 \mu \mathrm{g} / \mathrm{mL}$ (R30852801; Remel, Oxoid, Thermo Fisher Scientific, USA) in a 96-well cell culture plate at $37^{\circ} \mathrm{C}$ for 72 hours. On incubation, supernatant will be harvested for IFN- $\gamma$ quantification using the ELLA platform. Cells will be harvested and cell proliferation will be determined by the incorporation of 5-ethynyl-2'-deoxyuridine (EdU) at $10 \mu \mathrm{M}$ for 2 hours in T-cells using the Click-It EdU AF488 flow kit (C10420; Life Technologies, Carlsbad, California, USA). In first, cells will be stained with allophycocyanin (APC)-labelled anti-CD3 monoclonal antibodies (Beckman Coulter, Brea, California, USA), fixed with IOTest 3 fixative solution (Beckman 


\section{Box 3 List of post-transplant variables}

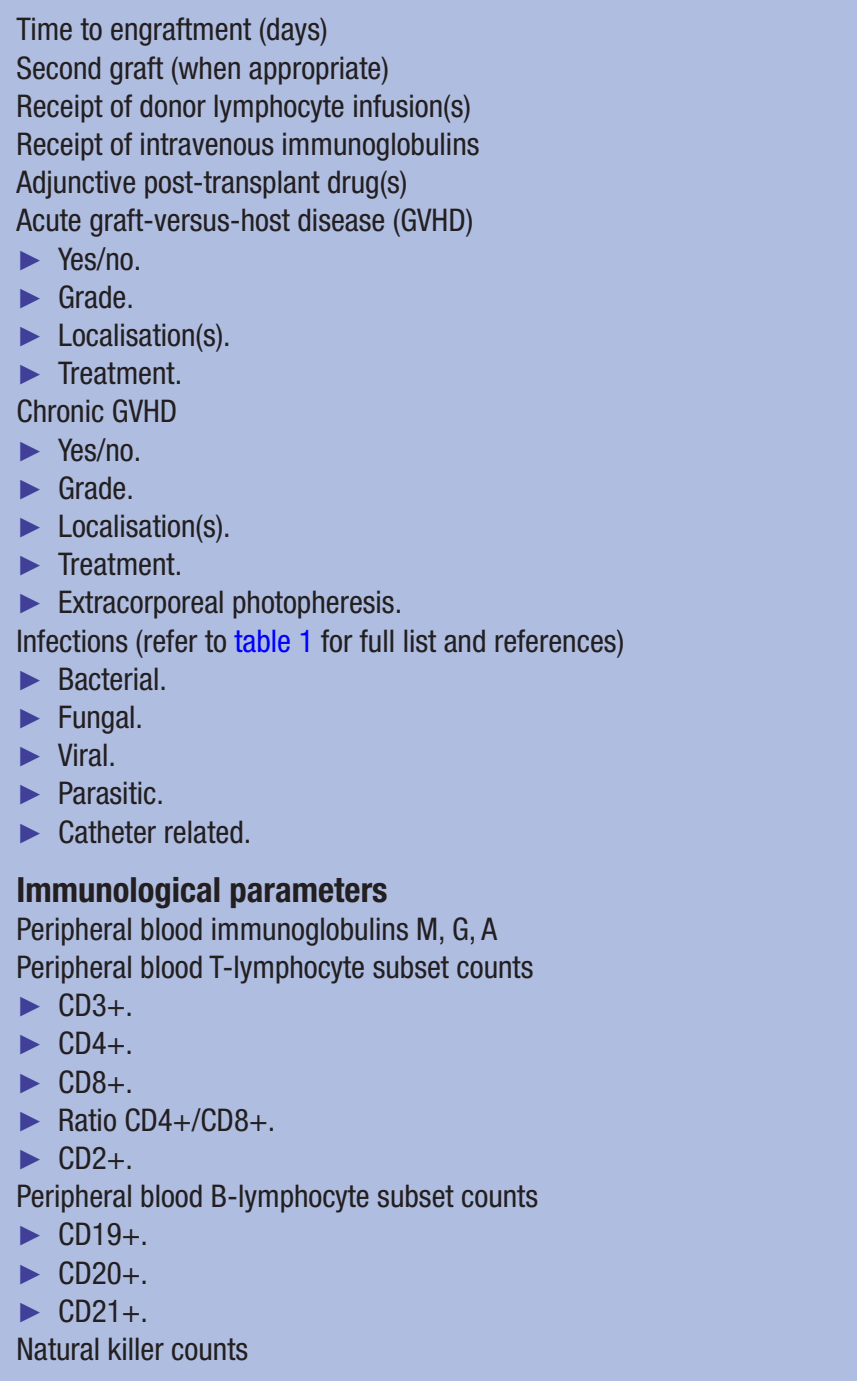

Coulter), and EdU will be activated with $100 \mu \mathrm{L}$ of a reaction cocktail containing Alexa Fluor 488 (AF488) azide (component of the Click-It). Flow cytometry analyses will be performed on a Navios flow cytometer (Beckman Coulter). $\mathrm{CD}^{+}$cells will be first selected among total events based on a monoparametric CD3-APC histogram. Then, the percentage of $\mathrm{EdU}^{+}$cells among $\mathrm{CD}^{+}$cells, along with the geometric means of fluorescence intensity of EdU-AF488 in this population, will be measured among $2.5 \times 10^{3} \mathrm{CD}^{+}$cells recorded. ${ }^{43}$

Using the immune functional assay described above, an innovative approach will consist in testing alternative recall antigens: varicella zoster virus (VZV) antigen (Microbix, Mississauga, Ontario, Canada), pneumococcal antigens (Pfizer, France) and tetanus toxoid (Pasteur Institute, Paris, France). The recall antigens stimulation will be performed on: (1) PBMCs, to quantify EdU+-cells and measure IFN- $\gamma$ after 7 days of incubation; (2) whole blood samples for 24 hours in order to extract RNA (QIAamp RNA Blood Mini Kit, QIAGEN, France) and perform a reverse transcription using the SuperScript VILO cDNA
Synthesis Kit (Thermo Fisher Scientific, France). TNF- $\alpha$ and IFN- $\gamma$ gene expression will be quantified by qPCR using Taqman probes (Thermo Fisher Scientific) on CFX Connect Real-Time PCR Detection System (Bio-Rad, Hercules, California, USA).

Routine cellular immunophenotyping will be processed at the Haematology and Immunology laboratories of Lyon university hospital (Lyon-Sud and Edouard Herriot hospitals, respectively). A large panel of B-cell and T-cell membrane markers associated with naïve or memory status will be investigated by flow cytometry. For B-cells, CD19+, CD20+, CD21+ and naïve B-cells (CD19+CD27-IgD+), memory B-cells commutated or not (CD19+CD27+IgD+/ IgD-) will be counted. For T-cells, central memory T-cells (CD4+CD45 RA-CCR7+), effector memory T-cells (CD4+CD45 RA-CCR7- and CD4+CD45 RA+CCR7-) will be counted in addition of routine $\mathrm{CD} 4+$ and CD8+ subsets.

Sera from venous blood collection will be frozen at $-20^{\circ} \mathrm{C}$ at the Institut des Agents Infectieux (CroixRousse Hospital, Lyon university hospital). Levels of specific serum IgG to seven serotypes included in the PCV13 vaccine (pn4, pn6B, pn9V, pn14, pn18C, pn19F, pn23F), and to pn1 and pn5 as markers of the immune response to PPV23, will be determined using a commercial ELISA (VaccZyme Anti-PCP IgG Enzyme Immunoassay Kit, Binding Site, UK). In addition, VZV-specific IgG and IgM (Laison VZV IgG and IgM, DiaSorin, Italy), diphtheria-specific and tetanus-specific IgG (VaccZyme Diphtheria or Tetanus Toxoid IgG Enzyme Immunoassay Kit) as well as HBV-specific anti-HBs antibody (anti-HBs2, Advia XP Centaur, SIEMENS, Germany) titres will be determined.

The biobanking of viable PBMC through cryopreservation will require a specific written consent. PBMC samples will be stored at the Centre de Ressources Biologiques Cytathèque (Lyon-Sud Hospital, Lyon university hospital) . Furthermore, the FIGHT cohort will provide the opportunity to establish four different types of biobanks, enabling further explorations of innovative biomarkers: (1) TruCulture plasma and mRNA from cellular pellet biobank from whole blood stimulated with LPS, SEB or unstimulated, to study immune response; (2) EDTA plasma biobank to study viral reactivation markers and soluble host biomarkers; (3) RNA biobank to study new transcriptomic host biomarkers (RNA will be extracted from whole blood collected in PAXgene Blood RNA tubes (Thermo Fischer Scientific)); (4) viable freezed PBMCs.

\section{Study sample size}

The VaccHemInf project focuses on a highly specific population of patients for whom few or no vaccine efficacy data are available based on transplant characteristics. As the main goal of the study is primarily descriptive (prevalence of responders at different follow-up times), a sample sizing is not required. However, taking into account that prevalence is not known at the selected follow-up times and that logistic regression models will be used, we based our calculation on Machin's rule of thumb suggesting the 
Table 2 Recommendations for vaccinations in HSCT recipients according to current French guidelines

\begin{tabular}{|c|c|}
\hline Immunisation target & Vaccine schedule \\
\hline Streptococcus pneumoniae & $\begin{array}{l}3 \text { doses of PCV13 in monthly intervals, starting } 3 \text { months post-HSCT. } \\
\text { Fourth dose boost injection with PPSV } 23 \text { at } 12-18 \text { months post-HSCT, substituted by PCV13 in } \\
\text { recipients with chronic GVHD. }\end{array}$ \\
\hline DTaPP & $\begin{array}{l}3 \text { doses of the paediatric vaccine (DTaPP) in monthly intervals starting at } 6 \text { months post-HSCT. } \\
\text { Boost injection with DTaPP at } 18 \text { months post-HSCT. } \\
\text { Lifelong revaccination with dTapP every } 10 \text { years. }\end{array}$ \\
\hline Influenza & $\begin{array}{l}1 \text { dose of the inactivated trivalent vaccine starting } 6 \text { months post-HSCT. } \\
\text { In case of ongoing outbreak, reduce the delay between HSCT and vaccination to } 3 \text { months. } \\
\text { Lifelong annual vaccination by } 1 \text { dose of the inactivated trivalent vaccine. } \\
\text { Vaccination of relatives and healthcare workers caring the patient is highly recommended. }\end{array}$ \\
\hline Hepatitis B & 4 injections $(20 \mu \mathrm{g})$ at $6,7,8$ and 18 months post-transplantation. \\
\hline
\end{tabular}

4CMenB, 4-component meningococcal B vaccine; DTaPP, diphtheria, tetanus, acellular pertussis and poliovirus (with full dose of diphtheria and acellular pertussis toxoids); dTapP, diphtheria, tetanus, acellular pertussis and poliovirus (with reduced dose of diphtheria and acellular pertussis toxoids); HSCT, haematopoietic stem cell transplantation; MC4V, tetravalent meningococcal conjugate vaccine; PCV, pneumococcal conjugate vaccine; PPSV, pneumococcal polysaccharide vaccine.

inclusion of 10 patients per estimated parameter in the model. ${ }^{44}$ For this reason, at least 50 patients are required.

\section{Statistical methods}

Qualitative variables will be expressed as count (percentage) while quantitative data will be expressed as median (IQR). The primary endpoint will be compared between V1 and V2, between V1 and V3 as well as between V1 and V4 regarding multiple variables related to haematological characteristics, treatment management, pattern of post-transplant immune recovery and transplant-related complications. Comparison will be performed using the Wilcoxon test, the Mann-Whitney U test, the $\chi^{2}$ test or the Fisher exact test, where appropriate. For the GMT, means and 95\% CI will be computed for the $\log 10$ transformed titres and then transformed back to the original units by exponentiation. For vaccine targets with low to moderate responder rates, the association between responders/non-responders endpoint and factor will be established using logistic regression. All factors associated with endpoint with a significance level $\mathrm{p}<0.15$ will be kept for multivariate logistic regression models. These models will be adjusted with at most two or three confounding factors chosen according to evidence-based literature. In case of relapse of the haematological disease, in case of death during follow-up or in case of loss to follow-up, patients will be included in the analysis provided that there is at least the prevaccination and one or more postvaccination assessment available. Analyses will be based on two-sided $\mathrm{p}$ values, with statistical significance defined by $\mathrm{p}<0.05$ and conducted with R V.3.4.4. Finally, appropriate multiple imputations (ie, at random or not) will be taken into consideration in the case of a relevant amount of missing values.

\section{Patient and public involvement}

No patients were involved in the design or implementation of this study. Study participants will be individually informed about their results during scheduled medical visits and will be given access, on demand, to the final publication of the study results.

\section{Ethics and dissemination}

The study is registered to the French Commission for Individual Data Protection and Public Liberties of Lyon's university hospital under the number 18-063 and has been approved by the national review board for biomedical research in March 2018 (Comité de Protection des Personnes Sud-Est V) under the title VaccHemInf-69HCL17_0769.

\section{Informed consent}

The identification of recipients included in the study will be kept anonymous and protected by a cryptographic code. Data will be anonymously extracted from medical records (HCL software). The informed and signed consent will be registered on the computerised record of each recipient. Full information of the objectives and the workflow of the study will be given and the possibility will be provided to the recipient to refuse to participate or to exit the study whenever chosen. A comprehensive notice will be distributed to the recipient summarising the protocol and the follow-up of the study.

\section{Dissemination}

Results will be communicated at scientific meetings and submitted for publication in peer-reviewed journals. 


\section{DISCUSSION}

\section{Strengths and limitations of the VaccHemInf study design}

The interest in designing a prospective cohort including all consecutive adult HSCT recipients who complete the vaccination schedule and have the full prevaccination and postvaccination assessments, independently of their complications and immunomodulatory therapy, is to test such a schedule in a 'real-life' setting. Another interest is the assessment of antibody titres at 24 months after vaccination, which has not been documented so far. We acknowledge the biases that contribute to overestimate the serum antibody concentrations: first, the heterogeneity in timing of recipient inclusion referred on referent haematologist's signal. The later after HSCT, the better immune recovery; second, some recipients receive intravenous Igs after transplantation, which may overestimate assessment of serological response to vaccines. We also acknowledge the bias due to the serology methods, notably for pneumococcus, which may be optimised through alternative methods such as the measurement of specific $\operatorname{IgG}_{2}$ antibodies or in vitro opsonisation test.

\section{Strengths and limitations of the VaccHemInf project database}

The purpose of immune functional assays is to measure deeper aspects of the immunity in response to vaccines. Precisely here, the variables collected in the database will potentially have an impact on the immune function, consequently altering the readout, interpretation, specificity and sensitivity of the assays. The Milieu Interieur Consortium has set up preliminary reference ranges of a healthy immune response and its natural variance. ${ }^{41}$ Similarly, in order to map the immune disorders, the 30 healthy donors of the VaccHemInf study will provide a reference panel essential for the evaluation of the 'in-range' or 'out-range' scale. In addition, the duration of the follow-up for this current project will last 24 months for a population of patients closely monitored by their referent physicians, with virtually no loss to follow-up. An added value might be to extend the duration of follow-up up to 5 years, on recipient's agreement, to sustain the quality of information. Nonetheless, we acknowledge that a potential confounder will be the important number of collected variables with a sample size that may not allow complex analysis or may likely be statistically underpowered. In order to assess the impact of functional immune status on vaccine response of HSCT recipients, a multicentre study with a larger number of patients is planned in the future.

\footnotetext{
Author affiliations

${ }^{1}$ Département des Maladies Infectieuses et Tropicales, Hospices Civils de Lyon, Lyon, France

${ }^{2} \mathrm{CIRI}$-Centre International de Recherche en Infectiologie, Inserm U1111, Université Claude Bernard Lyon, CNRS, UMR5308, Ecole Normale Supérieure de Lyon, Univ Lyon, Lyon, France

${ }^{3}$ Université Claude Bernard Lyon I, Lyon, France

${ }^{4}$ Département d'Hématologie Clinique, Hospices Civils de Lyon, Lyon, France

${ }^{5}$ Service d'Hygiène, Epidémiologie, Infectiovigilance et Prévention, Hospices Civils de Lyon, Lyon, France
}

6Équipe Épidémiologie et Santé Internationale, Laboratoire des Pathogènes Émergents, Fondation Mérieux, Centre International de Recherche en Infectiologie, Inserm U1111, Centre National de la Recherche Scientifique Unité Mixte de Recherche 5308, Ecole Nationale Supérieure de Lyon, Université Claude Bernard Lyon, Lyon, France

${ }^{7}$ Institut des Agents Infectieux, Hospices Civils de Lyon, Lyon, France

${ }^{8}$ Joint Research Unit, Hospices Civils de Lyon/BioMerieux, Lyon, France

${ }^{9}$ Soladis, Lyon, France

${ }^{10}$ Virpath, Inserm U1111, Lyon, France

Collaborators F Ader, V Alcazer, E Bachy, M Balsat, F Barraco, M Boccard, J S Casalegno, C Chidiac, A Conrad, S Ducastelle-Leprêtre, 0 Dumitrescu, D Dupont, V Escuret, T Ferry, G Fossard, E Frobert, S Goutelle, E Hodille, H LabussièreWallet, M-V Larcher, F Laurent, B Lina, G Lina, J Menotti, B Meunier, P Miailhes, G Monneret, F Morfin-Sherpa, E Paubelle, T Perpoint, M Rabodonirina, C Roure-Sobas, G Salles, X Thomas, S Trouillet-Assant, F Valour, F Wallet, M Wallon.

Contributors $\mathrm{AC}, \mathrm{MB}, \mathrm{FV}, \mathrm{VA}, \mathrm{KB}-\mathrm{P}, \mathrm{BM}, \mathrm{ST}-\mathrm{A}$ and $\mathrm{FA}$ were involved in trial design and drafting of the manuscript. All authors (AC, MB, FV, VA, A-TTS, CC, FL, PV, GS, KB-P, BM, ST-A and FA) were involved in critical revision of the article for important intellectual content and approved the final version.

Funding This research is being supported by an internal grant from the Hospices Civils de Lyon (Appel d'Offre Jeune Chercheur 2018).

Competing interests KB-P is an employee of bioMérieux $\mathrm{SA}$, an in vitro diagnostic company.

Patient consent for publication Not required.

Ethics approval Ethical approval has been obtained from the national review board for biomedical research in March 2018 (Comité de Protection des Personnes Sud-Est V) under the title VaccHemInf-69HCL17_0769.

Provenance and peer review Not commissioned; externally peer reviewed.

Open access This is an open access article distributed in accordance with the Creative Commons Attribution Non Commercial (CC BY-NC 4.0) license, which permits others to distribute, remix, adapt, build upon this work non-commercially, and license their derivative works on different terms, provided the original work is properly cited, appropriate credit is given, any changes made indicated, and the use is non-commercial. See: http://creativecommons.org/licenses/by-nc/4.0/.

\section{REFERENCES}

1. Li HW, Sykes M. Emerging concepts in haematopoietic cell transplantation. Nat Rev Immunol 2012;12:403-16.

2. Apperley J, Carreras E, Gluckman E. The 2012 revised edition of the EBMT-ESH handbook on haematopoietic stem cell transplantation. $2012 \mathrm{https}: / /$ ebmtonline.forumservice.net.

3. Baronciani D, Angelucci E, Potschger U, et al. Hemopoietic stem cell transplantation in thalassemia: a report from the European society for blood and bone marrow transplantation hemoglobinopathy registry, 2000-2010. Bone Marrow Transplant 2016;51:536-41.

4. Bosch M, Khan FM, Storek J. Immune reconstitution after hematopoietic cell transplantation. Curr Opin Hematol 2012;19:324-35.

5. D'Souza A, Fretham C. Current use and outcome of hematopoietic stem cell transplantation: CIBMTR Summary Slides. $2017 \mathrm{https} / / /$ www.cibmtr.org/ReferenceCenter/SlidesReports/SummarySlides/ pages /index.aspx.

6. Tomblyn M, Chiller T, Einsele H, et al. Guidelines for preventing infectious complications among hematopoietic cell transplantation recipients: a global perspective. Biol Blood Marrow Transplant 2009;15:1143-238.

7. Haut Conseil de Santé Publique (HCSP). Vaccination des personnes immunodéprimées ou aspléniques. 2014 http://www.hcsp.fr/explore. cgi/avisrapportsdomaine?clefr $=504$.

8. Hilgendorf I, Freund M, Jilg W, et al. Vaccination of allogeneic haematopoietic stem cell transplant recipients: report from the international consensus conference on clinical practice in chronic GVHD. Vaccine 2011;29:2825-33.

9. Ljungman $\mathrm{P}$, Cordonnier $\mathrm{C}$, Einsele $\mathrm{H}$, et al. Vaccination of hematopoietic cell transplant recipients. Bone Marrow Transplant 2009;44:521-6.

10. Rubin LG, Levin MJ, Ljungman P, et al. 2013 IDSA clinical practice guideline for vaccination of the immunocompromised host. Clin Infect Dis 2014;58:309-18. 
11. 7th European conference on infections in leukaemia guidelines for vaccination of patients with hematological malignancies and HSCT recipients. 2017 http://www.ecil-leukaemia.com/telechargements/ ECIL\%207\%20Vaccine\%20Part\%20I\% 20and\%20I\%20Final.pdf

12. Hahn M, Schnitzler P, Schweiger B, et al. Efficacy of single versus boost vaccination against influenza virus in patients with multiple myeloma. Haematologica 2015;100:e285-e288.

13. Engelhard D, Zakay-Rones Z, Shapira MY, et al. The humoral immune response of hematopoietic stem cell transplantation recipients to AS03-adjuvanted A/California/7/2009 (H1N1)v-like virus vaccine during the 2009 pandemic. Vaccine 2011;29:1777-82.

14. Reber A, Katz J. Immunological assessment of influenza vaccines and immune correlates of protection. Expert Rev Vaccines 2013;12:519-36.

15. Sorror ML, Maris MB, Storb R, et al. Hematopoietic cell transplantation (HCT)-specific comorbidity index: a new tool for risk assessment before allogeneic HCT. Blood 2005;106:2912-9.

16. Jagasia $\mathrm{MH}$, Greinix HT, Arora M, et al. National institutes of health consensus development project on criteria for clinical trials in chronic graft-versus-host disease: i. the 2014 diagnosis and staging working group report. Biol Blood Marrow Transplant 2015;21:389-401.

17. Lee SJ. Classification systems for chronic graft-versus-host disease. Blood 2017;129:30-7.

18. Cordonnier C, Engelhard D, Ljungman P, et al. Definitions of infectious diseases and complications after stem cell transplant, a proposal of infectious diseases working party of the EBMT. 2001 https://www.ebmt.org/Contents/About-EBMT/Who-We-Are/ ScientificCouncil/ Documents/IDWPdefinitions.pdf.

19. Ullmann AJ, Aguado JM, Arikan-Akdagli S, et al. Diagnosis and management of Aspergillus diseases: executive summary of the 2017 ESCMID-ECMM-ERS guideline. Clin Microbiol Infect 2018;24:e1-e38.

20. Pappas PG, Kauffman CA, Andes DR, et al. Clinical practice guideline for the management of candidiasis: 2016 update by the infectious diseases society of America. Clin Infect Dis 2016;62:409-17.

21. Skiada A, Lanternier F, Groll AH, et al. Diagnosis and treatment of mucormycosis in patients with hematological malignancies: guidelines from the 3rd European Conference on Infections in Leukemia (ECIL 3). Haematologica 2013;98:492-504.

22. Tortorano AM, Richardson M, Roilides E, et al. ESCMID and ECMM joint guidelines on diagnosis and management of hyalohyphomycosis: Fusarium spp., Scedosporium spp. and others. Clin Microbiol Infect 2014;20 Suppl 3:27-46.

23. Maschmeyer G, Helweg-Larsen J, Pagano L, et al. ECIL guidelines for treatment of Pneumocystis jirovecii pneumonia in nonHIV-infected haematology patients. J Antimicrob Chemother 2016;71:2405-13.

24. Styczynski J, van der Velden W, Fox CP, et al. Management of epstein-barr virus infections and post-transplant lymphoproliferative disorders in patients after allogeneic hematopoietic stem cell transplantation: sixth european conference on infections in leukemia (ECIL-6) guidelines. Haematologica 2016;101:803-11.

25. Ljungman $\mathrm{P}$, de la Camara $\mathrm{R}$, Cordonnier $\mathrm{C}$, et al. Management of CMV, HHV-6, HHV-7 and Kaposi-sarcoma herpesvirus (HHV-8) infections in patients with hematological malignancies and after SCT. Bone Marrow Transplant 2008;42:227-40.

26. Emery V, Zuckerman M, Jackson G, et al. Management of cytomegalovirus infection in haemopoietic stem cell transplantation. Br J Haematol 2013;162:25-39.

27. Cesaro S, Dalianis T, Hanssen Rinaldo C, et al. ECIL guidelines for the prevention, diagnosis and treatment of BK polyomavirusassociated haemorrhagic cystitis in haematopoietic stem cell transplant recipients. J Antimicrob Chemother 2018;73:12-21.
28. Matthes-Martin S, Feuchtinger T, Shaw PJ, et al. European guidelines for diagnosis and treatment of adenovirus infection in leukemia and stem cell transplantation: summary of ECIL-4 (2011). Transpl Infect Dis 2012;14:555-63.

29. Engelhard D, Mohty B, de la Camara R, et al. European guidelines for prevention and management of influenza in hematopoietic stem cell transplantation and leukemia patients: summary of ECIL-4 (2011), on behalf of ECIL, a joint venture of EBMT, EORTC, ICHS, and ELN. Transpl Infect Dis 2013;15:219-32.

30. Hirsch HH, Martino R, Ward KN, et al. Fourth European Conference on Infections in Leukaemia (ECIL-4): guidelines for diagnosis and treatment of human respiratory syncytial virus, parainfluenza virus, metapneumovirus, rhinovirus, and coronavirus. Clin Infect Dis 2013;56:258-66.

31. Singer M, Deutschman CS, Seymour CW, et al. The third international consensus definitions for sepsis and septic shock (Sepsis-3). JAMA 2016;315:801-10.

32. Martino R, Maertens J, Bretagne S, et al. Toxoplasmosis after hematopoietic stem cell transplantation. Clin Infect Dis 2000;31:1188-94.

33. Musher DM, Luchi MJ, Watson DA, et al. Pneumococcal polysaccharide vaccine in young adults and older bronchitics: determination of IgG responses by ELISA and the effect of adsorption of serum with non-type-specific cell wall polysaccharide. $J$ Infect Dis 1990;161:728-35.

34. Berger M. Immunoglobulin G subclass determination in diagnosis and management of antibody deficiency syndromes. J Pediatr 1987; $110: 325-8$

35. Schauer U, Stemberg F, Rieger $\mathrm{CH}$, et al. Levels of antibodies specific to tetanus toxoid, Haemophilus influenzae type b, and pneumococcal capsular polysaccharide in healthy children and adults. Clin Diagn Lab Immunol 2003;10:202-7.

36. Peltola H, Käyhty H, Virtanen M, et al. Prevention of Hemophilus influenzae type $\mathrm{b}$ bacteremic infections with the capsular polysaccharide vaccine. N Engl J Med 1984;310:1561-6.

37. Rodrigo MJ, Vendrell M, Cruz MJ, et al. Utility of the antibody response to a conjugated haemophilus influenzae type b vaccine for diagnosis of primary humoral immunodeficiency. Am J Respir Crit Care Med 2000;162:1462-5.

38. World Health Organization. Health topics: Immunization. 2018 http:// www.who.int/topics/immunization/en/.

39. Sarmati L, Andreoni M, Antonelli G, et al. Recommendations for screening, monitoring, prevention, prophylaxis and therapy of hepatitis $B$ virus reactivation in patients with haematologic malignancies and patients who underwent haematologic stem cell transplantation-a position paper. Clin Microbiol Infect 2017;23:935-40.

40. Rol ML, Venet F, Rimmele T, et al. The REAnimation Low Immune Status Markers (REALISM) project: a protocol for broad characterisation and follow-up of injury-induced immunosuppression in intensive care unit (ICU) critically ill patients. BMJ Open 2017; 7:e015734

41. Duffy D, Rouilly V, Libri V, et al. Functional analysis via standardized whole-blood stimulation systems defines the boundaries of a healthy immune response to complex stimuli. Immunity 2014;40:436-50.

42. Urrutia A, Duffy D, Rouilly V, et al. Standardized whole-blood transcriptional profiling enables the deconvolution of complex induced immune responses. Cell Rep 2016;16:2777-91.

43. Poujol F, Monneret G, Friggeri A, et al. Flow cytometric evaluation of lymphocyte transformation test based on 5-ethynyl-2' deoxyuridine incorporation as a clinical alternative to tritiated thymidine uptake measurement. J Immunol Methods 2014;415:71-9.

44. Machin D, Campbell MJ, Tan SB, et al. Comparing two independent groups for binary data. Sample Size Tables for Clinical Studies. 3 edn, 2011:30-41. 